\title{
Adsorption Characteristics of Cellulolytic Enzymes from the Anaerobic Fungus Piromyces sp. Strain E2 on Microcrystalline Cellulose
}

\author{
REMBRANDT DIJKERMAN, * MIKE B. F. VERVUREN, HUUB J. M. OP DEN CAMP, \\ AND CHRIS VAN DER DRIFT \\ Department of Microbiology and Evolutionary Biology, Faculty of Science, University of Nijmegen, \\ NL-6525 ED Nijmegen, The Netherlands
}

Received 29 August 1995/Accepted 16 October 1995

\begin{abstract}
Characteristics of the cellulolytic system of the anaerobic fungus Piromyces sp. strain E2 with respect to adsorption onto microcrystalline cellulose were examined. Cellulolytic enzymes were separated by gel filtration chromatography into a high-molecular-mass complex with an apparent mass of approximately 1,200 to 1,400 kDa and proteins of lower molecular weights. Adsorption of cellulolytic enzymes was not only very fast (within 2 min, equilibrium was attained) but also very effective: Avicelase, endoglucanase, and $\beta$-glucosidase activities from the high-molecular-mass complex were almost completely removed by Avicel. Adsorption of these enzyme activities was proportional and appeared to obey the Langmuir isotherm. For Avicelase, endoglucanase, and $\beta$-glucosidase activities, the maximum amounts adsorbed $\left(A_{\max }\right)$ and apparent adsorption constants $\left(K_{\text {ad }}\right)$ were 16.8, 600, and $33.5 \mathrm{IU} / \mathrm{g}$ and $284,6.93$ and $126 \mathrm{ml} / \mathrm{IU}$, respectively. The results of this study strongly support the existence of a multiprotein enzyme complex. This complex was found not to be specifically associated with cell wall fragments as judged by chitin determination.
\end{abstract}

Extracellular cellulases with a microbial origin have importance for the conversion of the cellulose component of lignocellulosic waste to fermentable sugars, i.e., glucose (4). The cellulases from the aerobic fungus Trichoderma reesei (12) have been studied most extensively in this context. Thus far, the low specific activity of most cellulases toward crystalline cellulose has prevented their industrial use for the production of glucose. Anaerobic fungi are a group of organisms that have been attracting attention for some time with regard to their cellulolytic capacity. Among these, the fungus Piromyces sp. strain E2, isolated from the feces of an Indian elephant (Elephas maximus), was shown to exhibit a high digestive activity toward plant cell wall polysaccharides $(18,20,21)$ and (filter paper) cellulose (17). Specific enzyme activities were high compared with those of aerobic fungal strains of $T$. reesei and Trichoderma viride, which are known to be the most powerful in cellulose hydrolysis $(2,6)$.

A crucial factor in the degradation of cellulose by bacterial and fungal cellulases is binding of these enzymes to the insoluble substrate $(5,10,11,16)$. It was found that the initial hydrolysis rate is proportional to the amount of enzyme initially adsorbed. Furthermore, Hogan et al. (8) reported that only initially adsorbed cellulases are responsible for cellulose hydrolysis and others may only play a minor role in this process. Binding of many microbial cellulases to cellulosic materials is widely investigated. Aerobic fungi, i.e., Trichoderma species, produce cellulolytic enzymes that possess cellulose binding domains (CBDs), which mediate binding of the enzymes (7). Although cloned cellulases (celA and celD) from the anaerobic fungus Neocallimastix patriciarum have been shown to exhibit cellulose binding capacity, it remains to be deter-

\footnotetext{
* Corresponding author. Mailing address: Department of Microbiology and Evolutionary Biology, Faculty of Science, University of Nijmegen, Toernooiveld 1, NL-6525 ED Nijmegen, The Netherlands. Phone: (31) 24 3652315. Fax: (31) 24 3553450. Electronic mail address: rem@sci.kun.nl.
}

mined whether these enzymes contain a discrete $\operatorname{CBD}(25,26)$. In anaerobic bacteria, e.g., Clostridium thermocellum, cellulolytic enzyme activities are associated in a multicomponent complex. This complex contains a noncatalytic scaffolding protein mediating binding to cellulose (15). A crystalline cellulose solubilizing factor from Neocallimastix frontalis was isolated by adsorption onto Avicel (22). This article is the first to describe a quantitative approach to the adsorption characteristics of the cellulolytic enzymes from anaerobic fungi with Piromyces sp. strain E2 as a model organism. The results are discussed in relation to the observation that anaerobic fungi produce a multiprotein complex of high molecular mass $(1,19,22-24)$, which was suggested to play a crucial role in the adsorption to and therefore, most likely, the hydrolysis of crystalline cellulose.

\section{MATERIALS AND METHODS}

Organism and growth conditions. Piromyces sp. strain E2 (ATCC 76762) was grown in 500-ml defined medium M2 with $0.5 \%$ (wt/vol) filter paper in 1-liter serum bottles as described previously (21). After growth stopped, as determined by hydrogen production (21), the crude culture filtrate (CCF) was centrifuged at $4^{\circ} \mathrm{C}$ for $20 \mathrm{~min}$ at $27,000 \times \mathrm{g}$ to remove cells and residual solid substrate. Crude filtrate was stored at $-20^{\circ} \mathrm{C}$ until use.

Enzyme preparation. CCF (1.8 liters) was concentrated to approximately 100 $\mathrm{ml}$ with a Minitan cassette (30-kDa cutoff; Millipore Corp., Bedford, Mass.) and subsequently to $10 \mathrm{ml}$ in an Amicon ultrafiltration cell over a YM-10 filter (Amicon, Danvers, Mass.). The concentrate was dialyzed for $18 \mathrm{~h}$ against $10 \mathrm{mM}$ morpholineethanesulfonic acid (MES) buffer containing $100 \mathrm{mM} \mathrm{NaCl}(\mathrm{pH}$ 6.5).

Gel filtration chromatography. The chromatographic system consisted of a model 6200 high-performance liquid chromatography (HPLC) system with a L-4000 UV detector (Hitachi, Tokyo, Japan). The concentrated and dialyzed CCF (5.0 ml; $145 \mathrm{mg}$ of protein) was applied to a Sephacryl S-300 HR column ( 2.5 by $95 \mathrm{~cm}$; Pharmacia LKB Biotechnology, Uppsala, Sweden), which was equilibrated and eluted with $10 \mathrm{mM}$ MES buffer containing $100 \mathrm{mM} \mathrm{NaCl}(\mathrm{pH}$ 6.5) at a flow rate of $0.5 \mathrm{ml} / \mathrm{min}$. The column was calibrated with a set of molecular weight markers (Sigma Chemical Co., St. Louis, Mo.) under identical conditions. Fractions collected $(5 \mathrm{ml})$ were screened for protein and (hemi)cellulolytic enzyme activities before and after the addition of Avicel. Maximum adsorption was achieved by adding $2 \mathrm{ml}$ of each fraction to $300 \mu \mathrm{l}$ of a $20 \%$ (wt/vol) suspension of Avicel (microcrystalline cellulose, type PH 105; Serva, Heidelberg, Germany) in $0.1 \mathrm{M}$ citrate-phosphate buffer ( $\mathrm{pH}$ 6.0). Incubation 




FIG. 1. Binding of cellulases from culture filtrate from Piromyces sp. strain E2 to microcrystalline cellulose. Relative adsorption was calculated as the ratio of bound activity to initially added enzyme activity. Symbols: $\mathbf{\square}$, Avicelase; $\bullet$, endoglucanase; $\boldsymbol{\Lambda}$, $\beta$-glucosidase.

and centrifugation were performed as outlined below. For other experiments, fractions were pooled as follows: fractions 32 to 42, high-molecular-mass (HMM) complex; fractions 46 to 80, low-molecular-mass (LMM) components. Specific activities (in international units per milligram) for Avicelase, endoglucanase, and $\beta$-glucosidase were, respectively, 0.11, 3.24, and 0.24 (for CCF), 0.23, 5.03, and 0.28 (for HMM complex), and 0.04, 1.70, and 0.24 (for LMM components).

Adsorption of cellulases on cellulose. The time required for attaining the adsorption equilibrium was determined as follows. The enzyme preparation was diluted to $500 \mu \mathrm{g}$ of protein $/ \mathrm{ml}$, and $1.8 \mathrm{ml}$ was added to $200 \mu \mathrm{lof} 20 \%$ (wt/vol) Avicel suspension in $0.1 \mathrm{M}$ citrate-phosphate buffer ( $\mathrm{pH}$ 6.0). The mixture was incubated by reciprocal shaking at $300 \mathrm{rpm}$. At different time intervals ( 2 to 15 $\mathrm{min})$, the reaction was stopped by centrifugation $(12,000 \times \mathrm{g}, 5 \mathrm{~min})$. Both adsorption and centrifugation were carried out at $4^{\circ} \mathrm{C}$ to minimize hydrolysis of the cellulose. Nonadsorbed protein and enzyme activities were measured in the supernatant.

To determine the amount of Avicel needed for maximal adsorption, different cellulase preparations were incubated separately with increasing Avicel concentrations ( 0 to $10 \mathrm{mg} / \mathrm{ml}$ ) for $20 \mathrm{~min}$. Protein concentrations were adjusted to 180 $\mu \mathrm{g} / \mathrm{ml}$. Incubation and centrifugation were performed as described above.

Electrophoresis. Sodium dodecyl sulfate-polyacrylamide gel electrophoresis (SDS-PAGE) was performed in $10 \%$ polyacrylamide slab gels in the presence of SDS $(0.1 \%$, wt $/ \mathrm{vol})$ as described by Laemmli (9). Enzyme samples were diluted (1:1) with sample buffer (62.5 mM Tris-HCl [pH 6.8]) containing $2.3 \%$ (wt/vol) SDS, $10 \%$ (wt/vol) glycerol, $5 \%$ (wt/vol) $\beta$-mercaptoethanol, and $0.01 \%(\mathrm{wt} / \mathrm{vol})$ bromophenol blue and incubated for $18 \mathrm{~h}$ at $20^{\circ} \mathrm{C}(17)$. SDS-PAGE molecular weight standards (high-molecular-weight calibration kits) were obtained from Bio-Rad Laboratories (Richmond, Calif.). Electrophoresis was conducted at $15^{\circ} \mathrm{C}$ with a constant current of $40 \mathrm{~mA}$ until the tracking dye reached the anode end of the slab gels. Zymogram analysis for the detection of endoglucanase and $\beta$-glucosidase activity was performed as described by Teunissen et al. (17). After staining for $\beta$-glucosidase activity, the gel was washed in distilled water (two times, 10 min each time) and subsequently stained for protein with Coomassie brilliant blue G-250 (Serva).

Enzyme assays. Enzyme assays were performed in duplicate at optimum $\mathrm{pH}$ and temperature as described by Teunissen et al. (21). All enzyme reactions were linear over the period of the assays. Enzyme and substrate controls were included in all assays. Units of activity (international units) are defined as micromoles of product released per minute.

Protein determination. The protein concentrations were determined with BioRad protein reagent with bovine gamma globulin as a standard. Protein adsorbed to Avicel was determined after alkaline extraction by the method of McKinley and Vestal (14). Briefly, the Avicel pellet with bound protein was suspended in $300 \mu \mathrm{l}$ of $0.5 \mathrm{M} \mathrm{NaOH}$ and incubated for $72 \mathrm{~h}$ at $20^{\circ} \mathrm{C}$ with mixing twice a day. After centrifugation for $5 \mathrm{~min}$ at $12,000 \times \mathrm{g}$, the supernatant was neutralized with $0.5 \mathrm{M} \mathrm{HCl}$, and the protein content was determined as described above.

Chitin determination. For the determination of chitin in the HMM pool derived from gel filtration, a modification of the method described by Chen and Johnson (3) was used. HMM fractions were pooled and dialyzed against MES buffer ( $10 \mathrm{mM}, \mathrm{pH} 6.5)$ with three buffer changes. The dialysate was divided into two portions of equal volumes. One portion was incubated with an Avicel suspension in $0.1 \mathrm{M}$ citrate-phosphate buffer under optimal conditions for adsorption (20 min, $50 \mathrm{mg}$ of Avicel per $\mathrm{mg}$ of protein). The other portion was treated with $0.1 \mathrm{M}$ citrate-phosphate buffer only. Buffer (10 mM MES [pH 6.5]) with Avicel added was used as a control. After adsorption and centrifugation, the supernatant was filtered over a Whatman glass-fiber filter (grade C; Whatman Ltd., Maidstone, United Kingdom) and subsequently freeze-dried. The lyophilisate was used for glucosamine (chitin monomer) analysis.



FIG. 2. Effect of Avicel concentration on binding of extracellular cellulolytic enzymes from Piromyces sp. strain E2. Enzyme preparations were CCF filtrate $(\bullet)$, pooled HMM fractions $(\bullet)$, and pooled LMM fractions $(\boldsymbol{\Delta})$. The relative adsorption of Avicelase (a), endoglucanase (b), and $\beta$-glucosidase (c) was calculated as described in the legend to Fig. 1. Initially added Avicelase, endoglucanase, and $\beta$-glucosidase activities were, respectively, $0.10,2.9$, and $0.22 \mathrm{IU}$ for CCF, 0.20, 4.53, and 0.25 IU for the HMM pool, and $0.03,1.5$, and 0.21 IU for pooled LMM fractions.

\section{RESULTS}

Optimization of cellulase adsorption. Adsorption of the cellulases from CCF of Piromyces sp. strain E2 onto microcrystalline cellulose appeared to be a very fast process. Within 2 min, maximal adsorption of Avicelase, endoglucanase, and $\beta$-glucosidase activity was obtained (Fig. 1). Under the conditions applied, 84.4, 76.4, and $26.9 \%$ of the activities added, respectively, were bound to the cellulose. Bound enzyme activities could not be desorbed with distilled water, sodium chloride (1 M), glycerol (10\%, wt/vol), CHAPS \{3-[(3-cholamidopropyl)-dimethyl-ammonio]-1-propanesulfonate; $50 \mathrm{mM}$, or urea $(5 \mathrm{M})$. On the basis of measurement of residual protein in the supernatant after Avicel treatment, it was calculated that $17 \%$ of the protein was adsorbed. Use of the method of McKinley and Vestal (14) to determine directly the amount of adsorbed protein to Avicel gave the same result.

Another important parameter affecting adsorption is the cellulose concentration. Adsorption onto Avicel was performed with CCF, HMM complex, and LMM components (see below). In Fig. 2, the relative levels of binding of the Avicelase, endoglucanase, and $\beta$-glucosidase activities are plotted against 

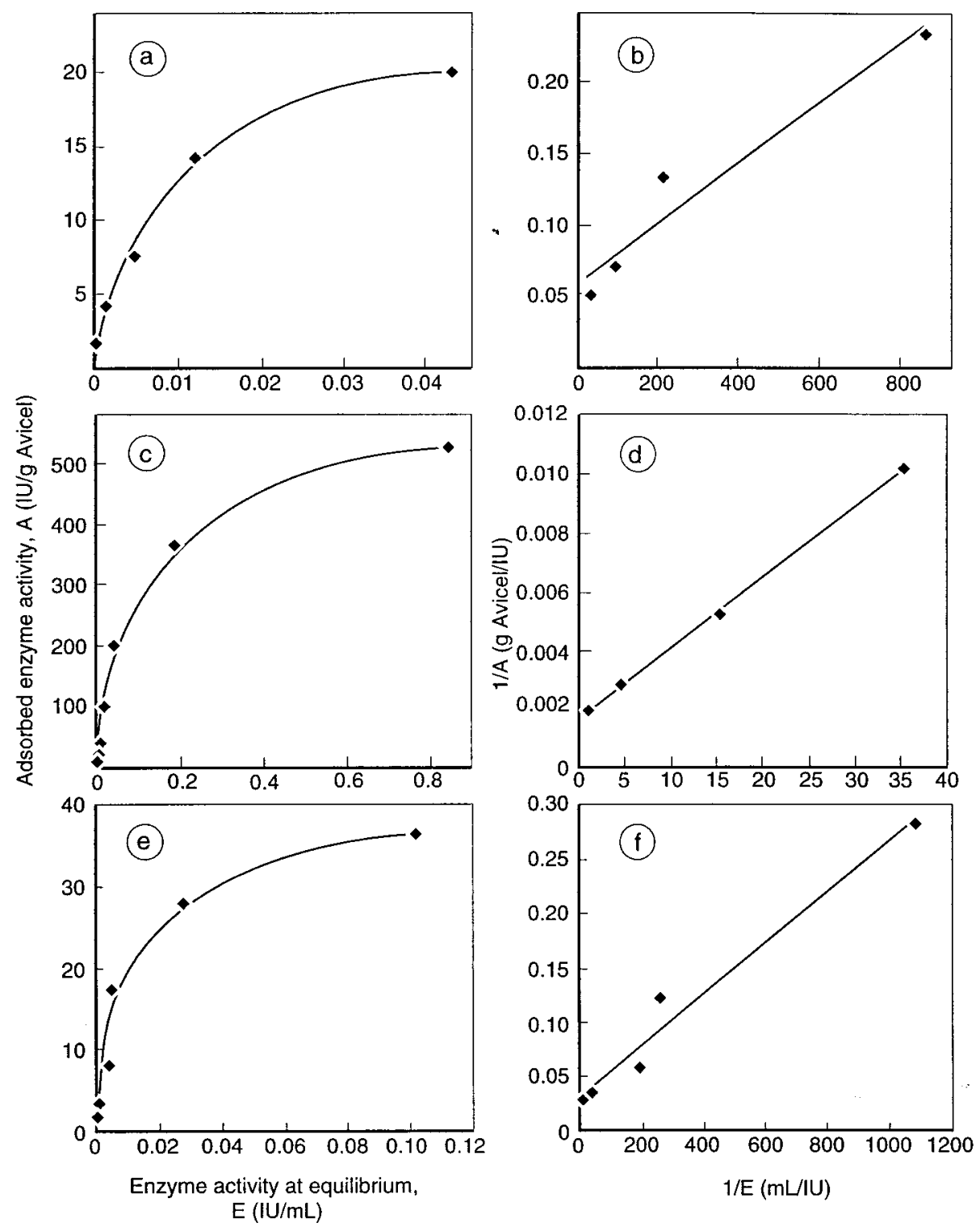

FIG. 3. Adsorption isotherms of HMM complex cellulases onto microcrystalline cellulose at $4^{\circ} \mathrm{C}$ and their corresponding reciprocal Langmuir plots. (a and b) Avicelase; (c and d) endoglucanase; (e and f) $\beta$-glucosidase.

the Avicel concentration. Maximal adsorption of the activities was attained at 28 to $56 \mathrm{mg}$ of Avicel per $\mathrm{mg}$ of protein for all preparations tested. Protein from CCF, HMM fractions, and LMM fractions bound at levels of $11.4,26.0$, and $4.5 \%$, respectively; both residual and bound protein was analyzed. High levels of binding (89 to $98 \%$ ) of Avicelase and endoglucanase activity were observed when CCF or HMM complex was used. Adsorption of these activities from the LMM fraction was significantly lower, i.e., 39\% for both Avicelase (Fig. 2a) and endoglucanase (Fig. 2b) activities. Binding of $\beta$-glucosidase activity from the three enzyme preparations is depicted in Fig. 2c. With $\mathrm{CCF}, 41 \%$ of this enzyme activity was removed by Avicel. When the HMM fraction was used, $81 \%$ of the enzyme activity was adsorbed. In contrast, hardly any activity was removed from the LMM fraction. The lower binding of $\beta$-glucosidase activity from the HMM fraction was due to the presence of some free enzymes (see also Fig. 5d). In the calculations described below, $\beta$-glucosidase values were corrected accordingly.

Langmuir parameters. The adsorption of cellulase can be described by the Langmuir equation:

$$
A=A_{\max } K_{\mathrm{ad}} E /\left(1+K_{\mathrm{ad}} E\right)
$$

where $A_{\max }$ and $K_{\text {ad }}$ are the maximum amount of enzyme activity adsorbed per unit weight of cellulose and the adsorption equilibrium constant, respectively, and $E$ is the enzyme activity in the liquid phase at the adsorption equilibrium. Equation 1 can be rearranged as:

$$
1 / A=1 /\left(A_{\max } K_{\mathrm{ad}} E\right)+1 / A_{\max }
$$

$A_{\text {max }}$ and $K_{\text {ad }}$ were determined from the plot of $1 / A$ against $1 / E$ (Fig. 3). The maximum amounts of adsorbed enzyme activity $\left(A_{\max }\right)$ for Avicelase, endoglucanase, and $\beta$-glucosidase were 


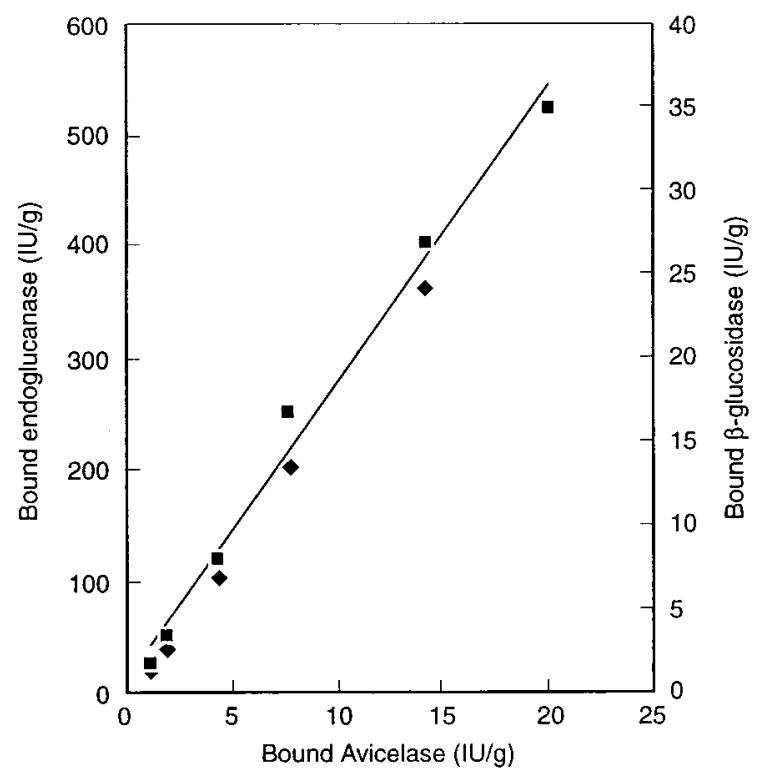

FIG. 4. Adsorption of Avicelase, endoglucanase, and $\beta$-glucosidase activities on Avicel at $4^{\circ} \mathrm{C}$. Adsorbed endoglucanase $(\diamond)$ and $\beta$-glucosidase (ם) activities are represented.

16.8, 600, and $33.5 \mathrm{IU} / \mathrm{g}$ of Avicel, respectively. For these activities, apparent adsorption constants $\left(K_{\mathrm{ad}}\right)$ of $284,6.93$, and $126 \mathrm{ml} / \mathrm{IU}$ were calculated. The amounts of bound Avicelase, endoglucanase, and $\beta$-glucosidase activities at various initial enzyme concentrations were found to be correlated linearly (Fig. 4), with a correlation coefficient of 0.998 .

Gel filtration chromatography. Concentrated and dialyzed CCF of Piromyces sp. strain E2 was applied to a Sephacryl S-300 HR column. The first protein peak (fractions 32 to 42 [HMM complex]) eluted at an apparent size of about 1,200 to 1,400 kDa. LMM components were represented by fractions 43 to 80 (Fig. 5a). Adsorption of protein onto Avicel was found to occur in nearly all fractions, but the highest removal was seen in the HMM fractions. Nevertheless, complete disappearance of protein was not observed, consistent with the results obtained from the optimization experiments (see above). Figures 5 a to d show enzyme activity patterns after gel filtration. Recoveries of the different activities were 60 to $70 \%$. This is most probably caused by loss of synergism (23). Activity towards Avicel was almost totally associated with the HMM complex. Avicel treatment, under optimal conditions, almost completely removed the cellulolytic enzyme activities from the HMM complex fractions. In the LMM fractions, exoglucanase and endoglucanase activities were lowered after adsorption onto Avicel but not as dramatically as they were in the HMM complex fractions. No adsorption of $\beta$-glucosidase activity was found in these fractions.

To investigate the possibility of specific association of HMM complex cellulases with fungal cell wall material, chitin analyses were performed. The pooled HMM complex fractions following gel permeation chromatography contained $181 \mu \mathrm{g}$ of chitin (analyzed as glucosamine). After Avicel adsorption, which removed the HMM complex, the supernatant was found to contain $185 \mu \mathrm{g}$ of chitin.
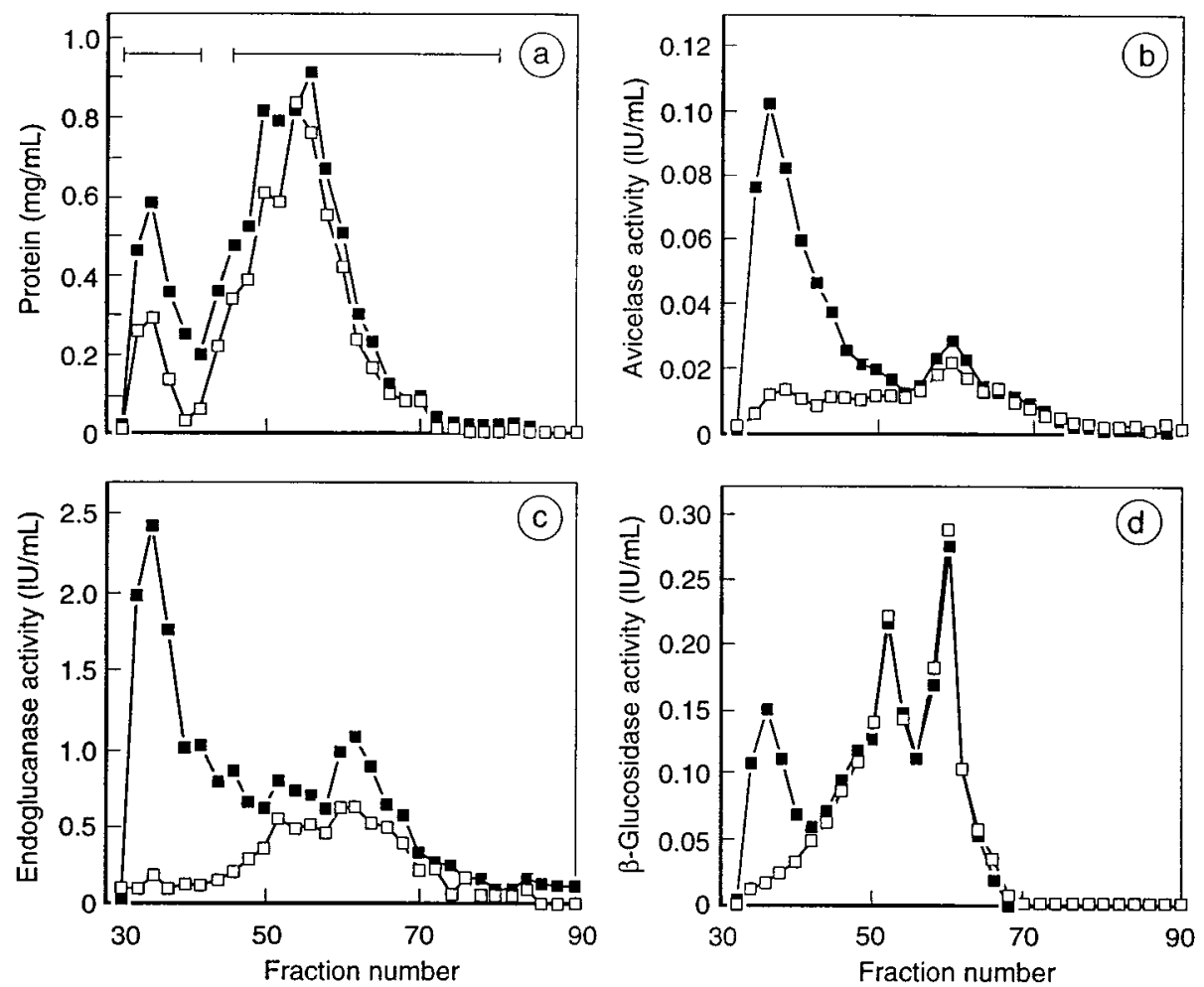

FIG. 5. Gel filtration of concentrated CCF from Piromyces sp. strain E2 on Sephacryl S-300 HR. Fractions (5 ml) were collected and assayed for protein (a), Avicelase (b), endoglucanase (c), and $\beta$-glucosidase (d) directly (closed symbols) and after adsorption on Avicel PH 105 (open symbols). HMM fractions (fractions 32 to 42 , left bar) and LMM fractions (fractions 46 to 80 , right bar) were pooled. See Materials and Methods for details. 



+ Avicel

(b)
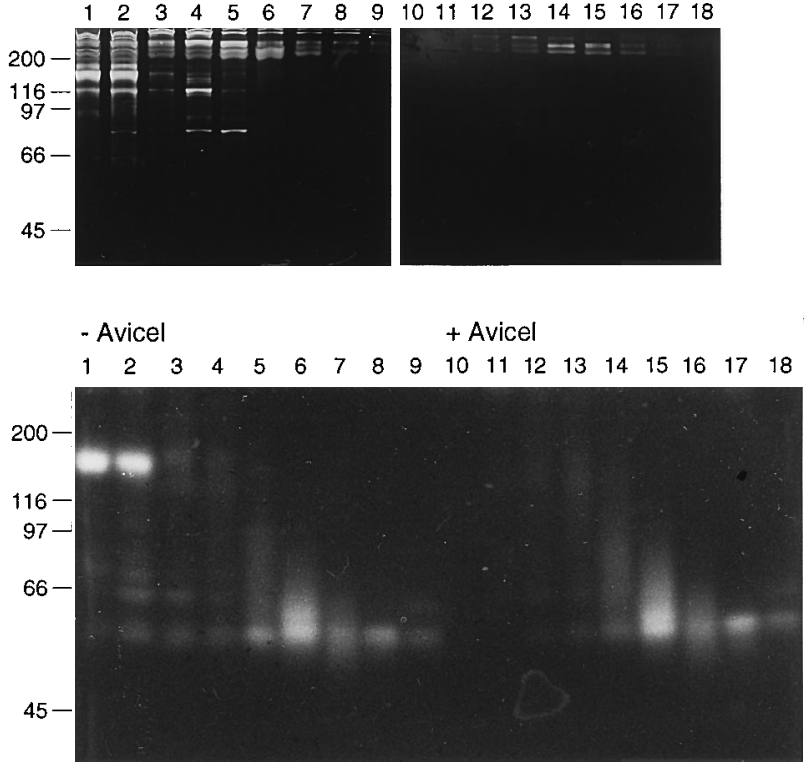

(C)

FIG. 6. Effect of Avicel on SDS-PAGE banding patterns of fractions obtained after Sephacryl S-300 HR gel filtration chromatography. For each sample (four fractions), 60 and $20 \mu \mathrm{l}$ were loaded on gels stained for $\beta$-glucosidase activity or protein and endoglucanase activity, respectively. Lanes 1 to 9 and lanes 10 to 18 in each figure represent fractions before and after adsorption with Avicel, respectively. Lanes: 1 and 10, fractions 31 to $34 ; 2$ and 11, fractions 35 to $38 ; 3$ and 12 , fractions 39 to $42 ; 4$ and 13 , fractions 43 to $46 ; 5$ and 14 , fractions 47 to $50 ; 6$ and 15 , fractions 51 to $54 ; 7$ and 16 , fractions 55 to $58 ; 8$ and 17 , fractions 59 to $62 ; 9$ and 18 , fractions 63 to 66 . (a) Protein pattern; (b) endoglucanase zymogram; (c) $\beta$-glucosidase zymogram. For details, see Materials and Methods.

Enzyme activity and protein patterns after SDS-PAGE analysis. SDS-PAGE was performed with fractions obtained after Sephacryl S-300 HR gel filtration, and the influence of adsorption with Avicel was examined. Figure 6 shows banding patterns after staining for protein and for endoglucanase and $\beta$-glucosidase activity. Lanes 1 to 9 and 10 to 18 in Fig. 6 a to c represent untreated and Avicel-treated fractions, respectively. The most obvious observation after the protein staining (Fig. 6a) was the disappearance of bands from HMM fractions at 64 , 61,67 , and $49 \mathrm{kDa}$ upon treatment with microcrystalline cellulose (lanes 1 and 2 compared with lanes 10 and 11). Removal of protein from the LMM fractions was considerably less: bands at 86,60 , and $53 \mathrm{kDa}$ in fractions 44 to 46 (lane 4 versus lane 13) were adsorbed after Avicel treatment. Nearly all en- doglucanase activity bands disappeared from the HMM fractions after Avicel treatment (Fig. 6b, lanes 1 and 2 versus lanes 10 and 11). Binding also occurred in LMM fractions, albeit to a lesser extent. Bands from these fractions at molecular masses of 214, 174, and $144 \mathrm{kDa}$ (lanes 3 to 8 compared with lanes 12 to 17) apparently did not adsorb onto Avicel. Distinct bands at about 97 and $70 \mathrm{kDa}$ were detected in HMM fractions as well as in LMM fractions (lanes 2 to 5). These activity bands were removed upon Avicel treatment in both cases (lanes 9 to 14).

The $\beta$-glucosidase activity staining is shown in Fig. 6c. A very distinct band at $133 \mathrm{kDa}$ was found in the HMM complex fractions, which disappeared completely after incubation with Avicel (lanes 1 and 2 versus lanes 10 and 11). This activity band was not detected in other fractions. Most distinct $\beta$-glucosidase activity bands in the LMM fractions had molecular masses at 59 and $56 \mathrm{kDa}$ and were not removed upon Avicel treatment (lanes 5 to 9 versus lanes 14 to 18 ).

\section{DISCUSSION}

The HMM complex of Piromyces sp. strain E2 obtained after gel filtration (19) contained all cellulolytic activities tested. Cellulolytic enzyme complexes were also found in other anaerobic fungi $(1,23,24)$. The formation of the HMM complex of Piromyces sp. strain E2 was induced by the presence of filter paper cellulose in the growth medium. No significant production of an HMM complex was found after growth on cellobiose in defined medium (data not shown). Medium containing rumen fluid and filter paper cellulose for $N$. frontalis resulted in a culture filtrate almost devoid of complex (23). The cellulolytic complex with a relatively low apparent molecular mass (334 to $670 \mathrm{kDa}$ ) that was reported for a Piromyces strain (1) was isolated after growth on cellobiose in medium containing rumen fluid. Recently, extracellular assembly of Clostridium cellulovorans cellulosomes in supernatant of cellobiose-grown cultures was demonstrated to be promoted by cellulose (13). This observation might explain the results obtained by Ali et al. (1).

Binding of all cellulolytic enzyme activities from the HMM complex was very fast and efficient ( $>80 \%$ adsorption), an aspect of great importance in the hydrolysis of cellulose. The physiological function of $\beta$-glucosidases is hydrolysis of small oligosaccharides to glucose, and normally, these enzymes lack a CBD. The removal of $\beta$-glucosidase activity in the case of Piromyces sp. strain E2 supports its presence in a multicomponent protein complex. The existence of a complex containing the three enzyme activities was substantiated by proportional adsorption of Avicelase, endoglucanase, and $\beta$-glucosidase activity. Further evidence was obtained from the Langmuir parameters. Assuming the presence of the enzymes in one complex implies that the $1 /\left(A_{\text {max }} K_{\text {ad }}\right)$ values, resembling the slope of the curves in Fig. 3b, d, and f, should be identical. The values calculated for Avicelase, endoglucanase, and $\beta$-glucosidase were $0.21,0.24$, and $0.24 \mathrm{~g} / \mathrm{l}$, respectively. Cellulolytic enzymes of a Piromyces strain and $N$. frontalis adsorbed to crystalline cellulose were desorbed with distilled water $(1,22)$. However, for Piromyces sp. strain E2, such a desorption was not observed, suggesting a very high affinity and a strong binding of these enzymes.

Only a few protein bands from the HMM fractions were removed upon treatment with crystalline cellulose, as judged by SDS-PAGE. Nonadsorbed bands may be the result of the presence of residual cell wall fragments, as confirmed by chitin analysis. Chitin was not removed by Avicel adsorption, indicating that cell wall fragments are not a functional part of the cellulolytic HMM complex. In contrast, association to some 
degree of the cellulases to fungal cell walls was suggested for $N$. frontalis on the basis of the fact that treatment of culture filtrate with chitinase inactivated cellulolytic activity (23). However, this is indirect evidence since the authors do not exclude the possibility of inactivation of the cellulolytic enzymes by impurities in the crude chitinase preparation used.

From zymogram analysis, it was evident that a distinct $\beta$-glucosidase $(133 \mathrm{kDa})$ is present in the HMM complex. Since this protein was not revealed after staining with Coomassie brilliant blue, the enzyme will have a very high specific activity. Four distinct protein bands without endoglucanase or $\beta$-glucosidase activity were effectively removed from the HMM complex by treatment with Avicel. A possible explanation is that one or more of these proteins act as (part of) a scaffolding protein, responsible for the attachment of the complex to cellulose, as is seen for the $C$. thermocellum cellulosome (15). However, the scaffolding protein for this organism is a highly glycosylated protein with a molecular mass of about $210 \mathrm{kDa}$.

Adsorption to cellulose of cellulases from a Piromyces strain (1) and $N$. frontalis (22) appeared to be restricted to the multiprotein cellulose-binding complex. The fact that some adsorption of LMM enzymes was observed in this study indicates that these enzymes either contain their own CBD or are fragments from the HMM complex containing a scaffolding protein or both. In contrast, Ali et al. (1) suggested that the single fungal enzymes do not contain a functional CBD and rely in their binding capacity completely on the association in a complex.

In summary, the HMM complex of Piromyces sp. strain E2 is not an artifact but a structural entity with strong affinity for crystalline cellulose. Whether the existence of this complex is dependent on environmental conditions, i.e., the presence of cellulose (13), and whether one or more scaffolding proteins are involved in the aggregation of this complex, as found for cellulosomes, remain to be elucidated. The adsorption data for the cellulolytic enzyme system for Piromyces sp. strain E2 will be of great importance in future applications of the enzymes. Furthermore, the role of the HMM complex, in particular, in the degradation of cellulose is the subject of additional investigations.

\section{ACKNOWLEDGMENTS}

We thank A. P. R. Theuvenet and J. A. L. I. Walters for their help in analyzing the data concerning the adsorption kinetics of the cellulolytic enzymes.

\section{REFERENCES}

1. Ali, B. R. S., L. Zhou, F. M. Graves, R. B. Freedman, G. W. Black, H. J. Gilbert, and G. P. Hazlewood. 1995. Cellulases and hemicellulases of the anaerobic fungus Piromyces constitute a multiprotein cellulose-binding complex and are encoded by multigene families. FEMS Microbiol. Lett. 125:1522.

2. Beldman, G., M. F. Searle-Van Leeuwen, F. M. Rombouts, and F. G. J. Voragen. 1985. Purification, characterization and comparison of all detectable endoglucanases, exoglucanases and $\beta$-glucosidases. Eur. J. Biochem. 146:303-308.

3. Chen, G. C., and B. R. Johnson. 1983. Improved colorimetric determination of cell wall chitin in wood decay fungi. Appl. Environ. Microbiol. 46:13-16.

4. Eriksson, K. E., and T. M. Wood. 1985. Biodegradation of cellulose, p. 469-504. In T. Higuchi (ed.), Biodegradation and biosynthesis of wood components. Academic Press Ltd., London.
5. Ghose, T. K., and V. S. Bisaria. 1979. Studies on the mechanism of enzymatic hydrolysis. Biotechnol. Bioeng. 21:131-146.

6. Ghosh, A., B. K. Gosh, H. Trimino-Vazquez, D. E. Eveleigh, and B. S. Montenecourt. 1984. Cellulase secretion from hyper-cellulolytic mutant of Trichoderma reesei Rut-C30. Arch. Microbiol. 140:126-133.

7. Gilkes, N. R., B. Henrissat, D. G. Kilburn, R. C. Miller, and R. A. J. Warren. 1991. Domains in microbial $\beta$-1,4-glycanases: sequence conservation, function and enzyme families. Microbiol. Rev. 55:303-315.

8. Hogan, C. H., M. Mes-Hartree, J. N. Saddler, and D. J. Kushner. 1990 Assessment of methods to determine minimal cellulase concentrations for efficient hydrolysis of cellulose. Appl. Microbiol. Biotechnol. 32:614-620.

9. Laemmli, U. K. 1970. Cleavage of structural proteins during the assembly of the head of bacteriophage T4. Nature (London) 227:680-685.

10. Lee, S. B., H. S. Shin, D. D. Y. Ryu, and M. Mandels. 1982. Adsorption of cellulase on cellulose: effect of physicochemical properties of cellulose on adsorption and rate of hydrolysis. Biotechnol. Bioeng. 24:2137-2153.

11. Lee, Y. H., and L. T. Fan. 1982. Kinetic studies of enzymatic hydrolysis of insoluble cellulose: analysis of the initial rates. Biotechnol. Bioeng. 24:23832406 .

12. Mandels, M. 1982. Cellulases. Annu. Rep. Ferment. Processes 5:35-78.

13. Matano, Y., J. S. Park, M. A. Goldstein, and R. H. Doi. 1994. Cellulose promotes extracellular assembly of Clostridium cellulovorans cellulosomes. J. Bacteriol. 176:6952-6956.

14. McKinley, V. L., and J. R. Vestal. 1985. Physical and chemical correlates of microbial activity and biomass in composting municipal sewage sludge. Appl. Environ. Microbiol. 50:1395-1403.

15. Poole, D. M., E. Morag, R. Lamed, E. A. Bayer, G. P. Hazlewood, and H. J. Gilbert. 1992. Identification of the cellulose-binding domain of the cellulosome subunit S1 from Clostridium thermocellum YS. FEMS Microbiol. Lett. 99:181-186

16. Ryu, D. D. Y., C. Kim, and M. Mandels. 1984. Competitive adsorption of cellulase components and its significance in a synergistic mechanism. Biotechnol. Bioeng. 26:488-496.

17. Teunissen, M. J., G. V. M. de Kort, H. J. M. Op den Camp, and J. H. J. Huis in 't Veld. 1992. Production of cellulolytic and xylanolytic enzymes during growth of the anaerobic fungus Piromyces sp. on different substrates. J. Gen. Microbiol. 138:176-182.

18. Teunissen, M. J., G. V. M. de Kort, H. J. M. Op den Camp, and G. D. Vogels. 1993. Production of cellulolytic and xylanolytic enzymes during growth of anaerobic fungi from ruminant and non-ruminant herbivores on different substrates. Appl. Biochem. Biotechnol. 39/40:177-189.

19. Teunissen, M. J., D. H. T. P. Lahaye, J. H. J. Huis on 't Veld, and G. D. Vogels. 1992. Purification and characterization of an extracellular $\beta$-glucosidase from the anaerobic fungus Piromyces sp. strain E2. Arch. Microbiol. 158:276-281.

20. Teunissen, M. J., H. J. M. Op den Camp, C. G. Orpin, J. H. J. Huis in 't Veld, and G. D. Vogels. 1991. Comparison of growth characteristics of anaerobic fungi from ruminant and non-ruminant herbivores during cultivation in a defined medium. J. Gen. Microbiol. 137:1401-1408.

21. Teunissen, M. J., A. M. Smits, H. J. M. Op den Camp, J. H. J. Huis in 't Veld, and G. D. Vogels. 1991. Fermentation of cellulose and production of cellulolytic and xylanolytic enzymes by anaerobic fungi from ruminant and nonruminant herbivores. Arch. Microbiol. 156:290-296.

22. Wilson, C. A., and T. M. Wood. 1992. The anaerobic fungus Neocallimastix frontalis: isolation and properties of a cellulosome-type enzyme fraction with the capacity to solubilize hydrogen-bond-ordered cellulose. Appl. Microbiol. Biotechnol. 37:125-129.

23. Wilson, C. A., and T. M. Wood. 1992. Studies on the cellulase of the rumen anaerobic fungus Neocallimastix frontalis, with special reference to the capacity to degrade crystalline cellulose. Enzyme Microb. Technol. 14:258-264.

24. Wood, T. M., S. I. McCrae, C. A. Wilson, K. M. Bhat, and L. A. Gow. 1988 Aerobic and anaerobic fungal cellulases, with special reference to their mode of attack on crystalline cellulose, p. 32-52. In J. P. Aubert, P. Béguin, and J. Millet (ed.), Biochemistry and genetics of cellulose degradation. Academic Press Ltd., London.

25. Xue, G. P., K. S. Gobius, and C. G. Orpin. 1992. A novel polysaccharide hydrolase cDNA (celD) from Neocallimastix patriciarum encoding three multifunctional catalytic domains with high endoglucanase, cellobiohydrolase and xylanase activities. J. Gen. Microbiol. 138:2397-2403.

26. Xue, G. P., C. G. Orpin, K. S. Gobius, J. H. Aylward, and G. D. Simpson. 1992. Cloning and expression of multiple cellulase cDNAs from the anaerobic fungus Neocallimastix patriciarum in Escherichia coli. J. Gen. Microbiol. 138:1413-1420. 